\title{
Analysis of Forest Fire Spread Trend Surrounding Transmission Line Based on Rothermel Model and Huygens Principle
}

\author{
Li Cunbin $^{1}$, Zhou Jing ${ }^{1 *}$, Tang Baoguo ${ }^{2}$ and Zhang $\mathrm{Ye}^{3}$ \\ ${ }^{1}$ School of Economics and Management, North China Electric Power University, Beijing \\ 102206, China \\ ${ }^{2}$ Department of Information Technology Shanxi Electric Power Corporation, Taiyuan 030001, \\ China \\ ${ }^{3}$ Huada Tianyuan (Beijing) Electric Power Technology Co., Ltd., Beijing 102206, China \\ zhoujing108@ncepu.edu.cn \\ Abstract \\ With the expansion of the power grid, transmission lines across forests are increasing. \\ Once forest fire occurs, it could threaten the transmission lines around or even cause them \\ trip out. Therefore, studying the spread of forest fire is important. This paper presents a \\ method based on Rothermel model and Huxgens principle to analyze forest fire spread trend \\ surrounding transmission line. Firstly, the principle of forest fire spread and the influence \\ factors of the forest fire spread around transmission lines are analyzed. Then, based on \\ Rothermel model and Huygens princtple, the forest fires spread trends under three different \\ conditions are simulated. By taking a transmission line of power grid in Shanxi Province as \\ an example, the simulation as implemented and works out the average velocity and the \\ consumed time during the forest fire spread from fire point to the transmission line under \\ three different conditions the result shows that the method is reasonable and valid.
}

Keywords: forest fire spread, Rothermel model, Huygens principle, visual simulation

\section{Introduction}

With the development of power industry in China, the electric power system is getting larger. Due to interprovihcial electricity transmission and the project of "West-East Electricity Transmission", much more transmission lines are laid out across forests with a high forest fire risk because of the global warming climate. Once forest fire occurs around, the transmission lines would be impacted with a high probability, sometimes even to threaten the stability of power grid operation. Therefore, to decrease hazards on transmission lines, analysis on forest fire spread trend is necessary and significant.

At ppesent, most researches only focus on forest fire spread trend itself but are rarely combined with transmission lines. In literature [1], a method to draw a realistic flame based on GIS terrain data and elevation map is illustrated. In literature [2], Wind as a factor is discussed on the real-time influences to forest fire spread. According to the principle of cellular automata, a new forest fire spread model is put forward in literature [3]. In literature [4], surface forest fire spread simulation method is analyzed and tested with grid algorithm.

In this article, an analysis method is put forward for forest fire spread trend around transmission lines, which is built based on Rothermel model and Huygens principle after fully analyzing factors to influence forest fire spread according to the characters of transmission lines in Shanxi province. This method can fairly predict the time of forest fire spreading from 
fire point to transmission lines, and precaution concerned entities to reduce trip out of transmission lines caused by forest fire.

\section{Forest Fire Spread Principle and Influence Factors}

\subsection{Forest Fire Spread Principle}

Once forest fire occurs, it will continuously spread around to even cause large-scale fire hazard. If the fire spreads to transmission lines, tripping accident would be induced. Continuous spread of forest fire is closely related to heat propagation [5]. Heat mainly propagates in the ways of conduction, convection and radiation. With interactions amongethe three ways, forest fire can fast spread around [6].

Heat conduction is a phenomenon caused by mutual collision of vast molectles inside a matter, which is shown as energy shift from a medium with a high temperature to the one with a low temperature. The speed of heat conduction depends on the thermal conductivity coefficient of medium. Thermal conductivity coefficient of combustible matter in forest is low, and heat transfers slowly. Heat conduction is the main way of heat transfer in underground forest fire.

Heat convection is a phenomenon that heat spatially transfers from one point to another one via flowing media. After firing, hot air goes up andcold one fills into so that heat convection is formed with a convection column over the burning area. This vertical heat transfer way may cause crown fire or junp fire in case $6 \mathrm{f}$ strong wind. Heat convection is the primary influence factor for the development of firio at the early stage.

Heat radiation is a phenomenon that a matter has a certain temperature so to radiate electromagnetic wave. The temperature is higher in burning area, the total volume of radiation is much high so that combustible matter around would be preheated and dewatered quickly to speed up fire spread.

Heat conduction thansfers heat inside a combustible matter, but heat convection and heat radiation transfer heat among different combustible matters. Forest fire could spread around in those three ways and cause large-scale fire hazards.

\subsection{Influence Factors on Transmission Line Forest Fire Spread}

In recent years, due to the greenhouse effect, forest fire occurs frequently. To mitigate damages of transmission line forest fire, many researchers have studied on forest fire spread mechanism and circumstances around transmission lines to show that there are many factors related to fire spread such as features of combustible matters, characters of soil, climate and so on. In this paper, according to the environmental characters in Shanxi province, combastible matter, terrain, wind, temperature and humidity are considered as major influence factors for forest fire spread around transmission lines.

2.2.1. Combustible Matter: The velocity of forest fire spread could be influenced by combustible matter's type, porosity, and moisture content at different extent [7].

Due to the influence of water and heat conditions, the zonation of latitude in Shanxi province is obvious with a warm temperature climate zone and summer green broadleaved forest vegetation zone in the south-east, and with a temperature climate zone and temperature grassland vegetation zone in the north-west. The plant types in the two vegetation zones are very different. The igniting point and spread velocity for combustible matters are also very different from each other. For instance, shiny or dead plant is very easy to burn with a high fire spread velocity. On the contrary, bulky trunk is not easy to be ignited with a low fire spread velocity. 
The porosity is shown with the ratio of approximate density to actual density of combustible matter. In order to adjust the porosity in experiment, the thickness of combustible matters will be adjusted by indirectly changing the porosity in this article. To some extent, increase of porosity will intensify combustion, and increase the height of flame so that radiation heat transferred to unburned area around also increases.

Moisture content is the ratio of water's weight to dry weight of combustible matter. Its value determinates the igniting point of combustible matter. The bigger is the value, the harder to burn is the combustible matter. Meanwhile, Moisture content also influences the velocity of forest fire spread. Higher moisture content means that more water could be used to bring heat away by evaporation so to lower the velocity of fire spread. The velocity will be zero when moisture content reach or beyond a limit value.

2.2.2. Terrain: Shanxi province is located on a loess mountainous plateau with arious and complex terrain, which not only influences the type of combustible matters and humidity, but also significantly impacts heat transfer. When the slope is steep water or combustible matter evaporates quickly, and the combustible matter is prone to ignition vice versa. Besides, the relative position between burned area and unburned area changes with the degree of slopes so to influence the volume of radiated heat and then the velocity of fire spread. In general, with the increase of slope degree, the velocity of fire spread increases, and fire on upward side of slope spreads quickly and the one on downiward side of slope spreads slowly.

2.2.3 Wind: Wind speed and wind direction are major factors to influence fire spread. Wind speed can accelerate evaporation of watter. Withry a certain range, the more intensive is the wind, the faster is the fire spread. The average wind speed varies from 1.4 to $4.5 \mathrm{~m} / \mathrm{s}$ and the highest wind speed commonly varies from 14 ? $20 \mathrm{~m} / \mathrm{s}$ in Shanxi province. Wind is more intensive in spring than it is in other seasons. Besides, transmission lines usually are laid out at higher ground where wind is more intensive and forest fire spread is influenced significantly. On the other hand, wind direction influences the direction of forest fire spread. Influenced by nainland low pressure, south and south-east wind dominates during summer half year, and affected by Inner Mongolia high pressure, north \&north-west wind dominate during winter half year in Shanxi province. Therefore, forest fire spread direction changes with seasons.

2.2.4 Temperature and humidity: Combustible matter's temperature and soil's temperature influence the ighiting point, and are indirectly influenced by air temperature so to affect forest fire spread. Meanwhile, air temperature and humidity significantly influence moisture content of combustible matter. The average temperature in Shanxi province varies from 3.7 to $13.8^{\circ} \mathrm{C}$. Influenced by horizontal distribution, it is warm in south and cool in north. Influenced by terrain, weather vertically varies obviously. Semi-arid climate dominates in Shanxi province but it is semi-humid climate in a small part of regions with high mountains and in southeastern Shanxi. The special climate condition influences the forest fire spread there.

\section{Forest Fire Spread Rothermel Model}

Forest fire spread model refers to a mathematic model established with simplified conditions without influence on the precision of model. This model can help to elicit quantitative relationship among various influence factors [8]. In terms of formulas of quantitative relationship, analysis on forest fire spread can be conducted, which is profound for forest fire prevention. Forest fire spread is a complex combustion \&movement process 
with interactions among factors of combustible matter, climate and terrain. Shanxi province is characterized with a complex environment of diverse vegetation, undulating terrain and changeable climate. Therefore, Rothermel model is taken as forest fire spread model for the study area in this article.

Based on law of energy conservation, Rothermel model is a mathematic model established in term of relative theories and experiences from forest fire experiment. It is a high abstraction from influence factors of forest fire spread with a good feasibility for the changeable climate and complex terrain in Shanxi province in China. With law of energy conservation, this model can derive the differential equation of average temperature in the process of heat radiation from fire ground. Then, combined with physic parameters and variables, the velocity of forest fire spread would be worked out and taken as a parameter of this model.

It is the advantage of Rothermel model to consider the process of front fire spread and continuous combustion in the burning area at the same time, For this reason, when this model is applied in field, various mixed combustible matters, which are even with a diameter at most $8 \mathrm{~cm}$, could only be chosen and the influence of combustible matters with a bigger diameter would be ignored. Since this model describes forest fire spread on a macro-scale, that is, a concept of "quasi stability". Therefore, parameters of fuel bed and terrain must continuously distribute and continuously change in a spaca and environmental parameters could not change too fast. As basic parameters, masŝ, surface area, volume of dried combustible matter, moisture content of combustible matter, wind speed, wind direction, terrain, and slope are input into this model.

The basic equation of Rothermel model is below.

$$
\left.R=\frac{I_{\varphi} \zeta \hat{C}_{(D)}}{\rho_{\rho} \hat{Q}_{i g}}+\bar{\phi}_{\omega}+\bar{\phi}_{s}\right)
$$

Where $R$ is the velocity' of forest fire spread in unit of $\mathrm{m} / \mathrm{min}, I_{r}$ is the intensity of flame reaction in anit of $k J /$ min $m^{2}, \zeta$ is the coefficient of heat flux, $\bar{\phi}_{\omega}$ is the correction coefficiont of wind speed, $\bar{\phi}_{s}$ is the correction coefficient of slope, $\rho$ is the density of combustible matter in unit of $\mathrm{kg} / \mathrm{m}^{3}, \varepsilon$ is the effective heat transfer coefficient of combustible matten and $Q_{i g}$ is the needed heat to ignite a unit mass combustible matter in unit of $\mathrm{kJ} / \mathrm{kg}$;

Based on regression equation of experiment data, correction coefficient equation of wind speed $\bar{\phi}_{\text {is }}$ worked out and expressed below.

$$
\begin{array}{r}
\bar{\phi}_{\omega}=C_{\omega}\left(3.2 U 8^{B_{\omega}}\left|\frac{\varepsilon}{\varepsilon_{o p}}\right|^{-E \omega}\right. \\
C_{\omega}=7.47 \exp \left(-0.133 \sigma^{0.55}\right) \\
B_{\omega}=0.025 \mathrm{z}^{2} 6^{5} \\
E_{\omega}=0.715 \exp \left(-3.59 \times 10^{4} \sigma\right) \\
\varepsilon_{o p}=3.348 \sigma^{-0.8189}
\end{array}
$$

Here $U$ is the wind speed inside the flame, and $\sigma$ is the ratio of surface area to volume of combustible matter. 
In the same way, correction coefficient of slope $\bar{\phi}_{s}$ is worked out and expressed below.

$$
\bar{\phi}_{s}=5.275 \sigma^{-0.3}(\operatorname{tg} \theta)^{2}
$$

Where $\theta$ is the value of slope degree.

Anderson had assumed that forest fire spread trend was an ellipse with a focus at the fire point as shown in Figure 1.

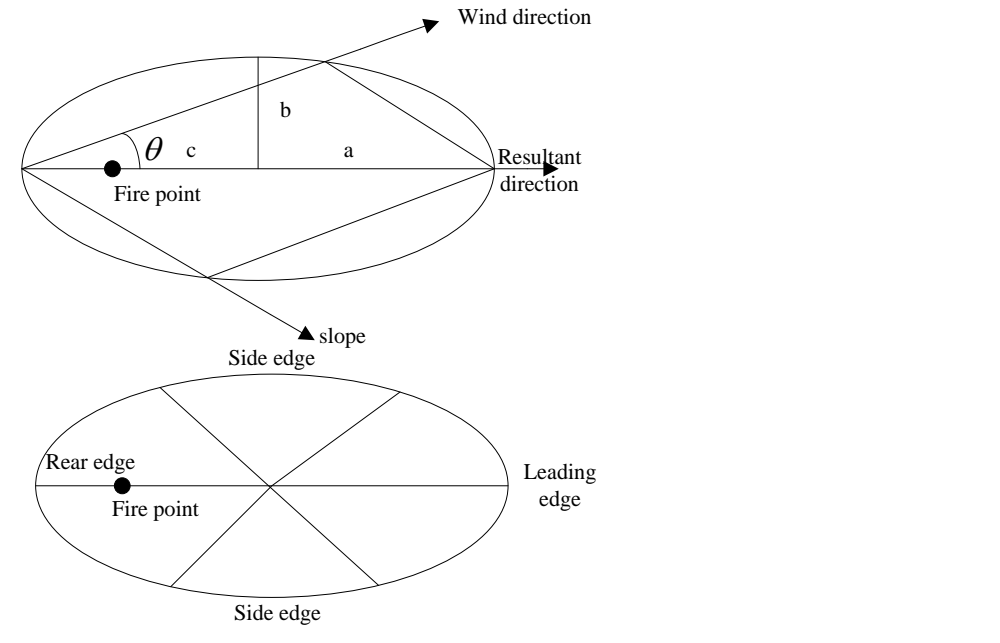

Figure 1. Éliptic Forest Fire Spread Trend

Then, combining a lot of experimental data and Rothermel model, he had worked out $L B$, the ratio of long axis $a$ to short axis $k$ of the ellipse as following.

$$
\angle B=0.936 \exp (0,2566 U)+0.461 \cdot \exp (-0.1548 U)-0.397
$$

Then Alexander had also worked out $H B$, the ratio of distance between the focus and the leading edge to the one between the focus and the rear edge here below.

$$
H B=0.5 \cdot\left[L B+\frac{L B^{2}-1}{L B}-\left(L B^{2}-1\right)\right]
$$

According to formulas (4) and (5), ellipse's long axis $a$, short axis $b$ and focus $c$ could be workectout in unit of $\mathrm{m} / \mathrm{min}$ as:

$$
a=\frac{1}{2} \cdot\left(R+\frac{R}{H B}\right), \quad b=\frac{1}{2} \cdot \frac{R+\frac{R}{H B}}{L B}, \quad \text { and } c=a-\frac{R}{H B} \text {. }
$$

Then the velocity for leading edge, rear edge and side edge could be worked out as $a+c$, $a-c$ and $b$ respectively.

\section{Forest Fire Spread Model based on Huygens Principle}

As for the established forest fire spread model, visual simulation is necessary. By means of visual simulation in a two-dimension space, objectives in a multi-dimension space could be transferred onto a flat for analyzing. Therefore, forest fire spread could be simulated in the way of two- dimension visualized simulation to offer customers the visual, concise and important 
information [13]. At present, simulation methods on forest fire spread include Border Interpolation algorithm, Boundary Extension algorithm, Maze algorithm and so on. Due to its own features, each method is available to specific forest fire spread model. In this article, forest fire spread simulation on real time has implemented by using Huygens principle combined with Rothermel model.

\subsection{Analysis on Huygens Principle}

In a traditional simulation method of forest fire spread, a simple ellipse is usually used to analyze each fire point during the process of forest fire spread. However, there is a big gap between the result of simulation and the reality so that the result could not precisely reflect the influences on forest fire spread by combustible matter, climate condition, and terain at different locations. However, Huygens principle could help to solve the aboye problem when it is applied to calculate the boundary parameters based on forest fire spread models.

In a forest fire spread simulation based on Huygens principle, a forest fire spread area is described as a polygon which dynamically changes with time 111. The shape of polygon is formed by connecting a serial control points on the perimeter of fire ground, and ellipse of fire spread in the next time step length can be calculated at each contol point in terms of fire spread model. Then the new boundary of fire ground could be determined. The mechanism is that each control point is treated as an independent fire point the spread velocity is calculated using Rothermel, and spread direction is determined by the superposition of wind direction and slope direction. According to the above analysin the result from simulation system based on Huygens principle is more precise. Besides, time is taken as the unit of step length in simulation so that synchronization anong fire environmental parameters could be easily realized when calculating.

\subsection{Procedures of Forest Fire Spread Simulation}

Based on Huygens principle, boundary parameters and variables of forest fire spread could be worked out following the betow 3 steps [14].

A. Select a serial of control points on the perimeter of initial fire point

B. Calculate parameters to form the spread ellipse in terms of Rothermel model

C. Select new control points on the spread ellipse and connect them to form the boundary of a new fire ground

Combined with Huygens principle, Rothermel model can realize a real-time simulation, which not only/can calculate the area and the perimeter of fire ground on real time, but also can modify the parameters of model according to fuel type, wind speed, slope degree at a specific location.

\section{Simulation of Forest Fire Spread}

\subsection{Simulation of Forest Fire Spread Trend}

In this article, experiment is conducted in the environment of power transmission lines in Shanxi province. According to the above simulation procedures, three patterns of forest fire spread trend are illustrated later. In Table 1, there are main input parameters and their values of simulation model.

A. Pattern 1: Forest fire spread trend on a flat ground under windless condition

Under windless condition, the forest fire spread trend on a flat ground is shown in Figure 2. It is seen that forest fire evenly spreads around and the trend approximates a circle. The center point of the circle represents the fire point. 
Table 1. Main Input Parameters of Simulation Model

\begin{tabular}{ll}
\hline \multicolumn{1}{c}{ Input parameter } & Value \\
\hline Initial forest fire spread velocity $R_{0}$ & 1.0 \\
Coefficient of heat flux $\zeta$ & 0.5 \\
Density of combustible matter $\rho$ & 0.12 \\
Effective heat coefficient $\varepsilon$ & $e^{-0.023}$
\end{tabular}

Needed heat to ignite a unit mass Combustible matter $Q_{i s}$

\section{Figure 2. Forest Fire Spread Trend on a Flal Ground Under Windless Condition}

B. Pattern 2: Forest fire spread trend on slope under windy condition

The terrain undulates where transmis ion lines are laid out in Shanxi province. The slope is steep. In this simulation, a slope with an angle of $30^{\circ}$ and a due west direction is selected, and the simulation resulf of forest/fire spread trend is shown in Figure 3. It is seen that fire on upward side of slope spreads quickly than the one on downward side of slope when there is only the influence factor of slope. The forest fire spread trend approximates an ellipse.

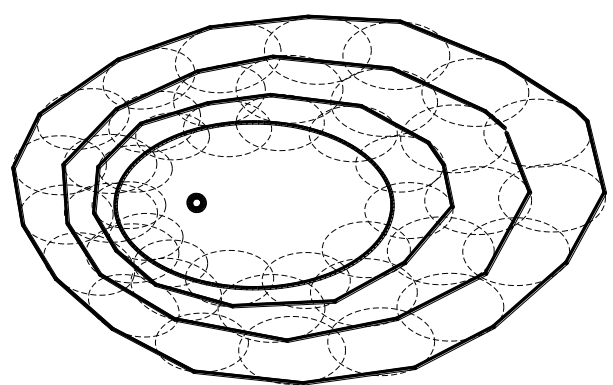

Figure 3. Forest Fire Spread Trend on a Slope Under Windless Condition

C. Pattern 3: Forest fire spread trend on a slope under windy condition

Influenced by intensive wind throughout a year in Shanxi province, transmission lines usually are laid out on high grounds in forest where wind speed is much high. Therefore, based on the climate conditions of winter half year in Shanxi province, the trend of forest fire spread is simulated by assuming that wind speed is $4 \mathrm{~m} / \mathrm{s}$, wind direction is in southeast, the degree of slope is $30^{\circ}$ and the direction of slope is due west. The simulation result is shown in 
Figure 4. It is seen that forest fire spreads quickly along the wind and slowly against the wind due to the monsoon. At this moment, forest fire spread is influenced by the degree of slope, wind speed and wind direction as well.

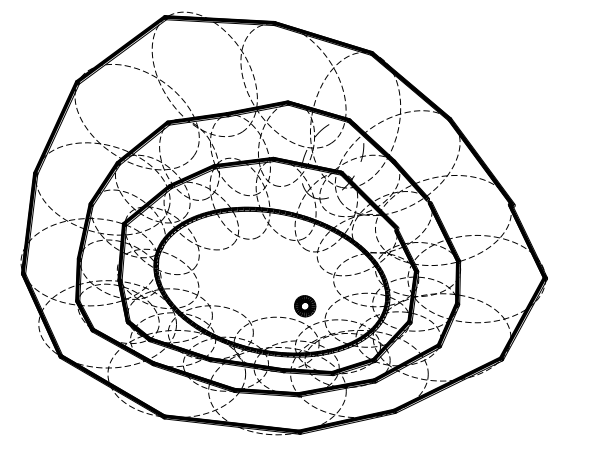

Figure 4. Forest Fire Spread Trend on a Slope Under Windy Condition

\subsection{Application Example of Forest Fire Spread Model}

To illustrate the validity of the forest fire spread model butt above, the average velocity of fire spread and the consumed time are calculated using this simulation model when fire spreads from the fire point to the transmission line located at the north-west of fire point in Figure 5. Here, the distance between fire point and the transmission line is $0.85 \mathrm{~km}$, assuming that the influenced area by forest fire stocated underand parallels with the transmission line.
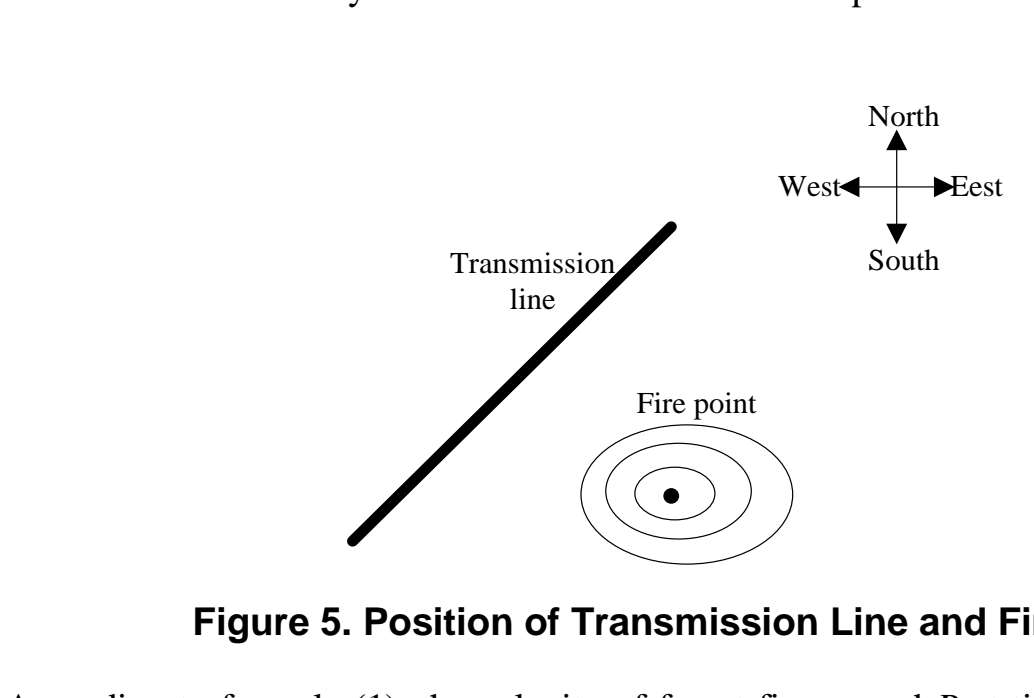

Figure 5. Position of Transmission Line and Fire Point

According to formula (1), the velocity of forest fire spread $R$ at time $\mathrm{t}$ can be worked out and then the size and the shape of fire ground can be determined. Finally, a judgment whether the fire has reached the transmission line or not, can be made. Here, the interval of time $\Delta t$ is set as 1 minute. The flow to predict the consumed time when forest fire reaches the transmission line is shown in Figure 6. 


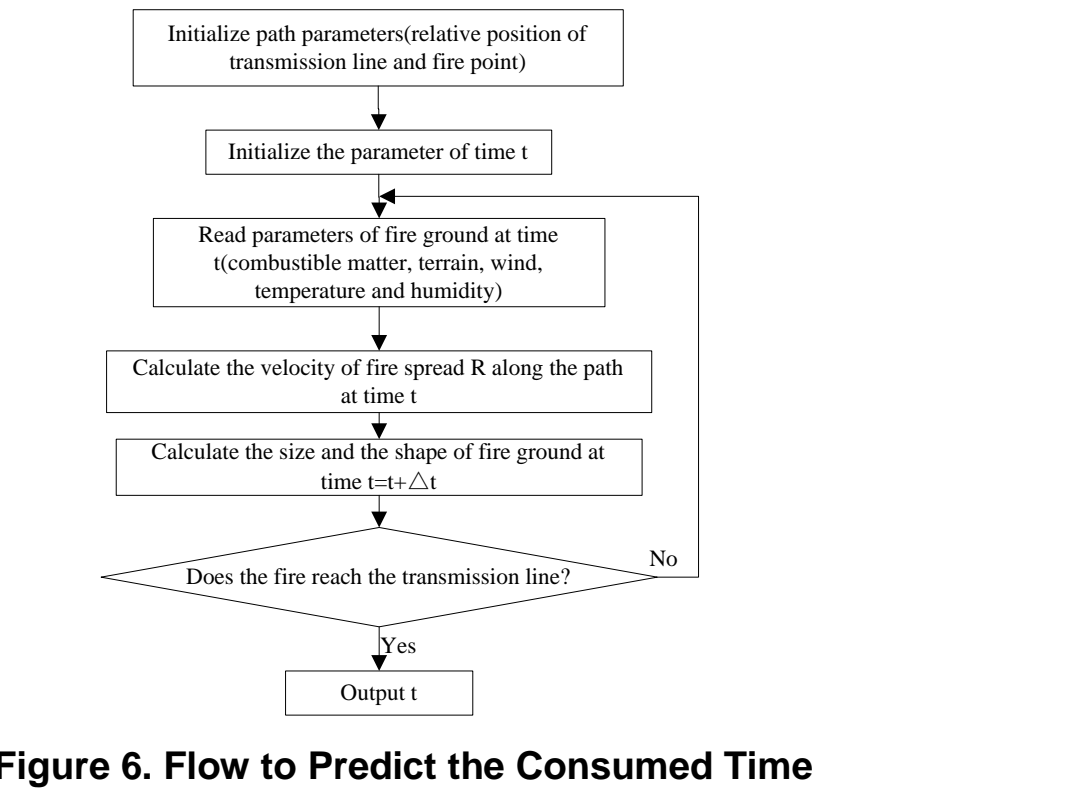

Under the three forest fire spread conditions mentioned above, the consumed time is predicted by the model and listed in Tablez

Table 2. Consumed Time and Average Velocity of Fire Spreading to
Transmission Line

\begin{tabular}{lccc}
\hline $\begin{array}{l}\text { Forest fire spreading } \\
\text { condition }\end{array}$ & $\begin{array}{c}\text { Pattern } \\
\mathbf{1}\end{array}$ & $\begin{array}{c}\text { Pattern } \\
\mathbf{2}\end{array}$ & $\begin{array}{c}\text { Pattern } \\
\mathbf{3}\end{array}$ \\
\hline Consumed time(min) & 69 & 96 & 19 \\
Average velogity $(\mathrm{km} / \mathrm{h})$ & 0.74 & 0.53 & 2.69 \\
\hline
\end{tabular}

It can be seen in Fable 2 that both average velocity and consumed time are different from each condition. The consumed time is the longest one in pattern 2 since the transmission line is located ona downward side of slop and fire spreads slowly on this kind of terrain than on a flat ground. The consumed time is the shortest one and average velocity is the fastest one in pattern 3 since wind speed and wind direction are major factors to influence fire spread, and the influence of terrain is minor under this condition. Therefore, more attention should be paid to the influence of wind in practice.

\section{Conclusions}

A Rothermel model and Huygens princple based analysis method is put forward in this article. Combined with the actual situation of power grid in Shanxi province, factors to influence the forest fire spread are considered overall. Then the forest fire spread trend is simulated in terms of Rothermel model and Huygens princple. The consumed time of fire spreading to transmission line under different conditions is compared. This method can simulate in real time by changing parameters according to the actual situation at any time, which is the biggest advantage comparing with traditional forest fire spread analysis methods. 


\section{Acknowledgements}

This paper is supported by Beijing Higher Education Young Elite Teacher Project (Grant No. YETP0704), the National Natural Science Foundation of China Project (Grant No. 71271084) and the Science and Technology key Project of Shanxi Province Electric Power Company (No. KJ2013-130).

\section{References}

[1] L. Shiguang, F. Yingchi and J. Yuqin, "Surface Fire Spreading Simulation with Realistic Impression [J]", Journal of Natural Disasters, vol. 21, no. 2, (2012).

[2] L. Rui, "The Research on Influence of Wind for Fire Spread Real-time Changes [J]”, Natural Sciénce Journal of Harbin Normal University, vol. 27, no. 5, (2011).

[3] Z. Feifei and X. Xinlu, "An Improved Forest Fire Spread Model and Its Realization [J]”, Geprnatics \&amp; Spatial Information Technology, vol. 35, no. 2, (2012).

[4] D. Fei, H. Zunze and L. Jiaqi, "Method of Ground Fire Boundaries Spread Modeling and Computer Simulation [J]", Fire Safety Science, vol. 10, no. 4, (2001).

[5] A. J. Chapman, "Heat Transfer", Macmillan Press. London: (1960), chapter 11

[6] J. Ende, "Forest Fire Spread Model [J]", vol. 2, (1986), pp. 31-33.

[7] L. Jieyu, "Overview of Forest Fuel Combustion Studies [J]", Journal of Northeast Porestry University, vol. 22, no. 4, (1994), pp. 95-101

[8] D. Q. Nguyen, R. P. Fedkiw and H. W. Jensen, "Physically Based Modeling and Animation of Fire", ACM Trans Graph, vol. 21, no. 3, (2002), pp. 721-728.

[9] M. Paul and S. K. Ghosh, "An Approach for Service Oriented Diseøvery and Retrieval of Spatial Data", International Workshop on Service Oriented Software Engineering. Shanghai: ACM Press, (2006), pp. 88-94.

[10] P. L. Andrews and B. L. P. Queen, "Fire Modeling and Nnformation System Technology [J]", Intenational Journal of Wildland Fire, vol. 10, (2001),pp. 343-352.

[11] H. E. Anderson, "Predicting Wind2driven Wildland Fire Size and Shape", USDA: Forest Service Research Paper, (1983), INT2305.

[12] M. E. Alexander, "Estimating The Length to Breadth Ratio of Elliptical Forest Fire Patterns", Proceedings of the Eighth Conference on Fire and Forest Meteorology Society of American Foresters, Bethesda, Maryland, (1985), pp. 287-304.

[13] S. Zhujin, "Forest-fire Spreading Simulation System with Huygens' Principle Based on GIS [D]", (2005).

[14] Z. Jiping and W. Haibui, "Á New Method of Determining the Boundary Surface Fire Spread [J]", Fire Safety Science, (1995), p. 9 .

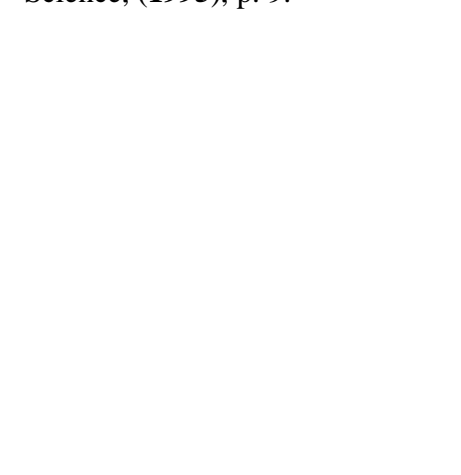

